\title{
A DEGRADAÇÃO DOS CURSOS HÍDRICOS URBANOS, UMA ABORDAGEM SOBRE GESTÃ̃ E EDUCAÇÃO AMBIENTAL
}

\author{
DEGRADACIÓN DE LOS CURSOS HÍDRICOS URBANOS, LA GESTIÓN Y LA \\ EDUCACIÓN AMBIENTAL
}

\author{
DEGRADATION OF URBAN WATER COURSES, MANAGEMENT AND \\ ENVIRONMENTAL EDUCATION
}

\author{
Ana Lucia Soares MACHADO ${ }^{1}$ \\ Izabel C. B. B. ZANETI ${ }^{2}$
}

Maria Inês Gasparetto HIGUCHI ${ }^{3}$

RESUMO: A Amazônia Central é a mais densa região hidrográfica e suas inúmeras sub-bacias vem sofrendo crescente degradação. A ocupação antrópica emerge nesse cenário como um forte causa de impacto negativo. Para reverter essa realidade aponta-se a educação e a gestão socioambiental como elementos importantes. Nesse estudo apresentamos uma análise histórica da qualidade da água nos cursos hídricos na cidade de Manaus (AM). Além disso, foram realizadas entrevistas com gestores para verificar aspectos relativos à gestão e iniciativas de educação ambiental para lidar com a realidade em curso. Os resultados demonstraram um grave processo de degradação do igarapé mesmo que ainda se tenha presença de vida aquática. As tentativas de proteção ambiental e intervenção educativa esbarram em entendimentos distintos e desmobilizados, que pouco agregam à plenitude esperada para uma gestão sustentável dos cursos hídricos urbanos.

PALAVRAS-CHAVE: Igarapé. Gestão socioambiental. Proteção ambiental.

RESUMEN: La Amazonia Central es una densa región hidrográfica y sus varias subcuencas sufren creciente degradación. La ocupación antrópica, en ese escenario, representa un importante impacto ambiental. Se plantea la educación ambiental y la gestión socio ambiental como importantes elementos para revertir tal situación. El presente estudio presenta un análisis histórico de la calidad del agua en uno de los arroyos de la ciudad de Manaus (BR). Además, se realizó una entrevista con gestores con el fin de conocer aspectos relativos à gestión e iniciativas en educación ambiental para hacer frente a la presente realidad. El resultado mostró un proceso de grave degradación del arroyo (Mindu), aunque tenga señales de vida acuática. Los intentos de protección ambiental e intervención educativa tropiezan en distintos entendimientos, que poco agregan a la plenitud esperada para la gestión sostenible de los cursos hídricos urbanos.

${ }^{1}$ Instituto Federal do Amazonas (IFAM-CMDI), Manaus - AM - Brasil. Eng. Controle e Automação. Doutora Desenvolvimento Sustentável. ORCID: <http://orcid.org/0000-0002-5977-2377>. E-mail: ana.machado@ifam.edu.br

${ }^{2}$ Universidade de Brasília (UnB-CDS), Brasília - DF - Brasil. Centro Des. Sustentável. Doutora Desenvolvimento Sustentável. ORCID: <http://orcid.org/0000-0002-7484-1799>. E-mail: Izabelzaneti.unb@gmail.com

3 Instituto Nacional de Pesquisas da Amazôna (INPA), Manaus - AM - Brasil. LAPSEA. Doutora em Antropologia Social. ORCID: <http://orcid.org/0000-0001-6525-4018>. E-mail: higuchi.mig@gmail.com

RIAEE - Revista Ibero-Americana de Estudos em Educação, Araraquara, v. 14, n. 3, p. 1124-1138, jul./set., 2019. e-ISSN: 1982-5587. 
PALABRAS CLAVE: Arroyo. Gestión socio ambiental. Protección ambiental.

ABSTRACT: The Central Amazon is the densest watershed region and its numerous under watershed have been suffering growing degradation. The anthropic occupation emerges in this scenario as a strong cause of negative impact. To reverse this reality the education and socioenvironmental management were pointed as important elements. In this study we present a historical analysis of the quality of water in the watercourses in the city of Manaus (AM). In addition, interviews with managers were conducted to verify aspects related to management and environmental education initiatives to deal with the ongoing reality. The results demonstrated a serious process of degradation of the water streams even though with a presence of aquatic life. Attempts at environmental protection and educational intervention run into distinct and demobilized understandings, which little accrete to the expected fullness of sustainable management of urban water courses.

KEYWORDS: Water stream. Socio-environmental management. Environment protection.

\section{Introdução}

No estado do Amazonas, concentra-se a maior reserva de água doce superficial do planeta em quantidade e vazão. Contudo, em Manaus, as águas urbanas das sub-bacias se encontram severamente poluídas. O sistema de gestão ambiental tem em suas mãos a árdua tarefa reverter o estado dos igarapés ${ }^{4}$ que entrecortam a cidade numa situação menos dramática, uma vez que apresentam altos níveis de degradação. Esses cursos hídricos, outrora objeto de orgulho dos Manauaras, hoje se veem transformados em esgotos a céu aberto.

O crescimento insustentável do município de Manaus não difere da realidade das demais metrópoles brasileiras, seguiu um modelo de crescimento e não de desenvolvimento. As consequências do crescimento têm afetado a todos sem discriminação e fronteiras. Apesar de todos sofrem as consequências, grande parte da sociedade permanece omissa diante dessa situação de degradação hídrica. Se por um lado pouco fazem para reverter tal cenário, por outro, pouco procuram de modo efetivo, cobrar das autoridades o compromisso de uma gestão sustentável.

O objetivo desse trabalho foi mostrar o processo de degradação dos igarapés ao longo dos anos e os conflitos vivenciados na gestão socioambiental e nos processos educativos propostos para reverter tal situação. Para tanto tomou-se como estudo de caso o igarapé do

\footnotetext{
${ }^{4}$ Palavra indígena, assim definida pelo Dicionário Houaiss da Língua Portuguesa: "canal natural estreito e navegável por pequenas embarcações, que se forma entre duas ilhas fluviais ou entre uma ilha fluvial e a terra firme".
}

RIAEE - Revista Ibero-Americana de Estudos em Educação, Araraquara, v. 14, n. 3, p. 1124-1138, jul./set., 2019. e-ISSN: $1982-5587$. 
Mindu como referência de análise, uma vez que este é culturalmente uma identidade da cidade. É o maior igarapé que corta a cidade de leste a oeste num trajeto de $25 \mathrm{~km}$.

Nesse estudo de caso de caráter descritivo exploratório, foram analisadas amostras da água do igarapé para verificar seu estado de poluição ambiental para posicionar o estado atual com os dados históricos obtidos a partir da pesquisa documental. Foram ainda realizadas entrevistas semiestruturadas com os gestores municipais para verificar como se posicionam diante do processo de gestão e educação ambiental.

\section{A degradação do Mindu no tempo e no espaço}

A degradação do Igarapé do Mindu tem estreitas ligações com o crescimento da cidade, evidenciando a inter-relação entre passado e presente que podem comprometer o futuro desses cursos hídricos, ou seja do antes belo e limpo, para o atual sujo e degradado. No início, Manaus era uma pequena vila que pelo fato de ser cercada por igarapés, se orgulhava por essa situação geográfica. Com o tempo, os igarapés centrais foram sendo degradados de tal forma que esse cenário edílico se tornou um cenário degradante. A história pode nos auxiliar a entender.

\section{Os igarapés de Manaus até a década de 1980}

A partir da instalação da Zona Franca e a busca por emprego e melhores condições de vida, a cidade começou a crescer em ritmo acelerado e desencadeou a prática de ocupação irregular de terras públicas e privadas. Até a década de 1970, as ocupações estavam concentradas nas zonas Sul, Centro Sul, Oeste e Centro Oeste. Em relação a urbanização e formação da cidade de Manaus, Oliveira (2001), Nogueira et al. (2007), entre outros, relatam a ocupação desordenada às margens dos igarapés da cidade, como também apresentam a influência da criação da Zona Franca de Manaus (ZFM) no agravamento desse quadro, principalmente devido ao contingente humano vindo do interior do estado e de outros estados brasileiros e a falta de políticas públicas para o enfrentamento dessa realidade.

Segundo o Relatório Final do Fórum sobre as Ocupações Desordenadas em Manaus (2004), a década de 1980 foi considerada a ‘década das invasões’, pois as ocupações irregulares continuaram a ocorrer, mas em direção às zonas leste e norte da cidade. Essas ocupações seguiam os cursos dos igarapés, transformando-os e degradando-os. A água que era limpa e cristalina passou a ser poluída de forma avassaladora. Essa realidade foi constatada por Fonseca, Salem e Guarim (1982) que analisaram a baixa qualidade das águas do Rio Negro na 
orla de Manaus, foz do igarapé do São Raimundo. Com o agravamento do lançamento de efluentes domésticos no leito dos igarapés nas áreas urbanas em Manaus, Bringel (1986) verificou essa poluição nos demais igarapés.

Fonseca, Salem e Guarim (1982) e Bringel (1986) ao analisaram as condições da qualidade das águas, se valeram de pontos de coleta distintos, mas todos evidenciaram a realidade degradante dos igarapés. As análises demonstraram que havia mudanças significativas nos parâmetros físicos, químicos e biológicos da água, de tal forma que havia evidências de grande diminuição da fauna aquática nesses cursos hídricos. Isso não bastou como referência, pois à medida que ocorria ocupação populacional às margens dos igarapés, mais impactos eram adicionados nesses cursos hídricos atingindo inclusive grandes calhas como o do Rio Negro. Todos os igarapés que entrecortam a cidade são lançados nesse rio, o qual, pelo volume de água, acaba exercendo a função de autodepurador. Apesar da grandiosidade do Rio Negro, que é fonte da captação de água para tratamento e atendimento à população de Manaus, em breve pode apresentar problemas de poluição que até pouco tempo consideravam-se inatingíveis.

Conforme a percepção dos moradores que vivem nas margens do igarapé, "neste período o igarapé era limpo e suas águas utilizadas para lavar louças, roupas e lazer" e que "as crianças viviam no igarapé e ninguém ficava doente". As informações dos moradores conferem com a pesquisa de Bringel, que não analisou as águas próximas as nascentes, do curso superior, pois eram preservadas, tendo como ponto inicial o igarapé na altura do bairro São José (Ponte do Sete). Para os moradores o igarapé, era admirado e considerado importante, porém lançavam seus dejetos diretamente nele, por falta dos serviços públicos de coleta. A realidade de poucas condições econômicas fazia com que tais moradores utilizassem o igarapé como via de esgoto, pois para eles "não tem outro jeito". Esse hábito pode ser uma prática cultural, em muitas situações não são reconhecidas como insustentáveis.

\section{Transformação contínua dos igarapés - década de 1990}

Manaus crescia de forma intensa e desordenada, os canais de muitos igarapés já eram utilizados como esgotos, mas foi nessa década que outro fator passou a ser causador de alterações ambientais: a retirada da cobertura vegetal das margens do igarapé. Com isso veio o assoreamento. Mesmo diante dessa realidade a cidade de Manaus continuou a avançar nas ocupações dos mananciais, provocando aumento do desmatamento, não apenas nas margens dos igarapés, como também em toda a área urbana. Essa situação passa a influenciar também 
nas alterações da temperatura, na umidade relativa do ar e no regime pluviométrico da cidade Fearnside (1997). O rápido crescimento também passou a aumentar problemas sociais.

Novas ocupações irregulares na Zona Leste avançaram, provocando mais alterações que contribuíram para uma forte degradação no igarapé do Mindu no sentido médio curso e, posteriormente, o curso superior. Nos estudos realizados pelo laboratório do Instituto Nacional de Pesquisa na Amazônia (INPA), o estado de degradação dos igarapés em área urbana era desanimador (Tabela 1).

Tabela 1 - Análise da qualidade da água no igarapé do Mindu (1998)

\begin{tabular}{|c|c|c|c|c|c|c|c|c|}
\hline \multirow{2}{*}{\multicolumn{9}{|c|}{$\begin{array}{c}\text { FEVEREIRO - } \\
1998\end{array}$}} \\
\hline & & & & & & & & \\
\hline PONTOS DE COLETA & $\begin{array}{l}\mathrm{NH}_{4}{ }^{+} \\
\mathrm{mg} / \mathrm{L}\end{array}$ & $\begin{array}{l}\mathrm{Fe} / \mathrm{T} \\
\mathrm{mg} / \\
\mathrm{L} /\end{array}$ & $\begin{array}{c}\mathrm{Fe} / \mathrm{Sol} \\
\mathrm{mg} / \mathrm{L}\end{array}$ & $\underset{\mathrm{Og} / \mathrm{L}}{\mathrm{O}}$ & $\mathbf{p H}$ & ${ }^{\circ} \mathrm{C}$ & Turb. & C.E. $(\mu \mathrm{S} / \mathrm{cm})$ \\
\hline Pq das Nascentes & 0,1 & 0,500 & 0,100 & 5,80 & 5,00 & 29 & 48 & 30,0 \\
\hline Grande Circular & 5,3 & 2,500 & 0,400 & 3,60 & 5,80 & 29 & 80 & 120,0 \\
\hline Colina do Aleixo & 6,0 & 1,800 & 0,200 & 1,80 & 6,20 & 30 & 65 & 110,0 \\
\hline Conj. Petros & 7,5 & 1,700 & 0,200 & 1,00 & 6,20 & 31 & 40 & 150,0 \\
\hline Pq do Mindu & 6,0 & 2,000 & 0,250 & 4,00 & 6,20 & 29 & 55 & 140,0 \\
\hline Av. Paraiba & 6,0 & 1,700 & 0,250 & 5,50 & 6,20 & 29 & 52 & 140,0 \\
\hline
\end{tabular}

Fonte: Relatório Bacias Hidrográficas: Projeto Avaliação dos Recursos Hídricos da Região Metropolitana de Manaus, INPA (2001).

Após 13 anos da primeira análise, estudos realizados em 2001 mostraram que somente as nascentes permanecem preservadas, no entanto as regiões situadas até dois quilômetros da nascente principal já têm suas primeiras alterações devido à fixação da população nessas áreas Cleto Filho (1998); Cleto Filho e Walker (2001). Os autores verificaram que no período de 1995 foi observada a alteração da macrofauna de invertebrados aquáticos, ou seja, diminuição da biodiversidade de organismos típicos de ambientes aquáticos isentos de eutrofização e aumento de macrófitas e outros organismos adaptados e resistentes a esses ambientes.

\section{Os igarapés na metrópole de Manaus - década de 2000}

Após três décadas de um processo acelerado de expansão urbana, foi somente em 2001 que a Prefeitura Municipal produziu um novo Plano Diretor Urbano Ambiental para Manaus (PDMM), regulamentado em 2002, substituindo o que estava em vigência desde 1975. Com o PDMM ficou estabelecido as diretrizes concernentes às questões dos igarapés em áreas urbanizadas, o Art. 10 no Inciso II, do PDMM: II - Programa de Proteção e Valorização dos Ambientes Naturais e dos Cursos d 'Água, objetivando a proteção dos rios e igarapés e de suas 
margens e a conscientização da população para a sua conservação e fiscalização, Lei Municipal $\mathrm{n}^{\circ} 671$, de 04 de novembro de 2002.

No entanto, o PDMM não cumpriu suas propostas e por isso passa por processo de revisão desde 2011. Apesar das tímidas investidas, as questões socioambientais no município ainda são tratadas com descaso pelo poder público. A população vê nos noticiários locais, os problemas recorrentes das ocupações irregulares, do desmatamento, das enchentes e da poluição nos igarapés. Os mais atingidos, no entanto, são os moradores que vivem nas margens dos igarapés. Eles pouco mudam seus hábitos, como esperam sem sucesso ações do poder público que possa aliviar o convívio com as mazelas, a pobreza e a poluição.

A expansão urbana a partir de 2000 continua no sentido zona Leste, em 2002 passou de 60 para 110 novos bairros com pouca estrutura de serviços de esgoto. A cidade de Manaus tem se tornado, ao longo dos anos, ambientalmente insustentável. Apesar dessa realidade ser disseminada por gestores públicos e população, poucas mudanças na qualidade hídrica do igarapé do Mindu.

\section{Qualidade hídrica do igarapé do Mindu: 1985 - 2007}

As águas na Região Hídrica Amazônica, de acordo com a classificação de Junk (1983), são rios de águas claras (Rio Tapajós), límpidas, apresentando características químicas entre as de águas brancas (Rio Solimões) e pretas (Rio Negro). O rio Negro, provém da drenagem dos escudos das Guianas e Brasileiro, a cor preta é resultado de substâncias fúlvicas e húmicas dissolvidas, que têm alta concentração de $\mathrm{Na}+\mathrm{e} \mathrm{K}+$. Essas características diferem dos cursos d'água em outras regiões do Brasil. Devido a essas especificidades, o padrão de qualidade para as águas da bacia Amazônica difere dos critérios estabelecidos pela Resolução do Conselho Nacional do Meio Ambiente CONAMA 357 (2005). Para tanto, foi adotada a sugestão de Bringel (1986) quanto ao padrão de qualidade das águas dos igarapés de Manaus, conforme Tabela 2.

Tabela 2 - Padrão de qualidade das águas dos igarapés da cidade de Manaus

\begin{tabular}{|c|c|c|c|}
\hline Características físicas equímicas* & Máxima & Mínima & Média** \\
\hline $\mathrm{Ph}$ & 4,73 & 3,2 & 4,02 \\
\hline Condutividade Elétrica (C.E.) $\mu \mathrm{S} \mathrm{cm} \mathrm{c}^{-1}$ & 90,0 & 11,0 & 27,0 \\
\hline Oxigênio Dissolvido OD mg/L & 6,0 & 2,0 & 3,0 \\
\hline $\mathrm{NH}_{4} \mathrm{mg} / \mathrm{L}$ & 0,30 & 0,05 & 0,12 \\
\hline
\end{tabular}


Os parâmetros físicos e químicos analisados desde o início do processo de ocupação das margens e adjacências do Igarapé do Mindu até o período de 2007 vêm validar as informações coletadas em campo, quanto ao estado de degradação desse curso d'água. Os pontos analisados referem-se a três regiões diferentes, ou seja, nascente e (curso superior); bairro Petros (médio curso) e Pq do Mindu (baixo curso).

Os parâmetros comparados ao longo dos anos foram: Potencial de Hidrogênio - pH; Condutividade elétrica; Oxigênio Dissolvido e Íon amônio, conforme Figura 1:

Figura 1 - Série Histórica - Ph, Condutividade, O.D e NH4+, I. Mindu
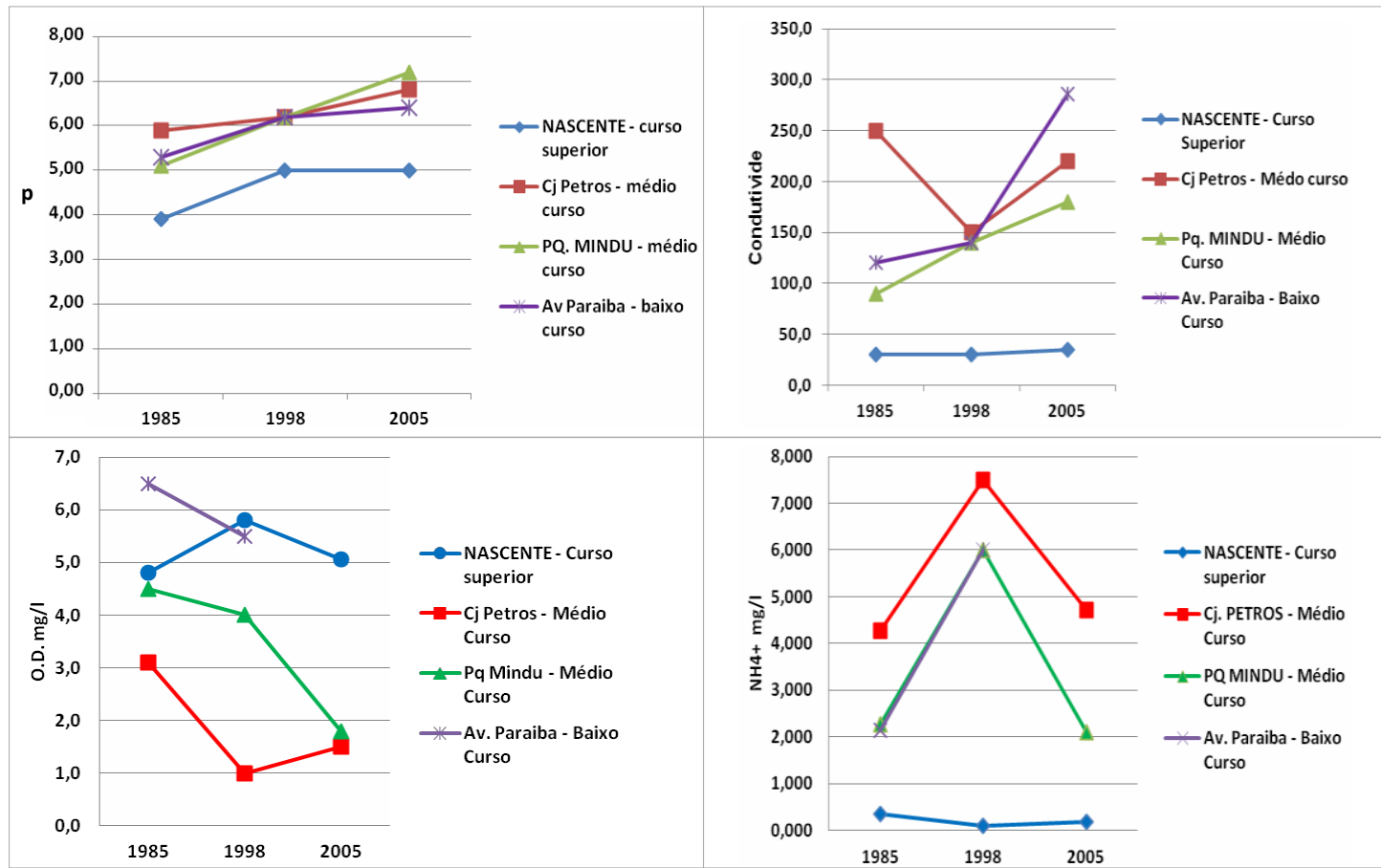

Fonte: Bringel (1986); Melo, Silva e Miranda (2005); Silva et al. (2007).

Conforme verificado no gráfico, as nascentes, entre os anos de 1985 e 1998, sofreram alterações significativas e nos anos seguintes foi mantido o valor para o $\mathrm{pH}$, que está dentro do padrão aceitável para águas pretas. Quanto aos demais locais analisados, por estarem localizados entre as áreas antropizadas, observou-se a mesma tendência de aumento, alcançando a alcalinidade, o que demonstra alterações em sua qualidade quanto ao $\mathrm{pH}$. Pinto et al. (2009), também apontam para a mesma variação de pH, devido às interferências antrópicas; dessa forma pôde-se constatar um comportamento homogêneo para o Ph.

A Condutividade Elétrica (CE), a medida que resulta da aplicação de uma força elétrica, é dependente da concentração de íons (sais) dissolvidos. Quanto maior a quantidade de íons 
dissolvidos, maior a condutividade elétrica. De acordo com Silva et al. (2007), as águas naturais nos igarapés dessa região são pobres em íons dissolvidos, logo, a condutividade é baixa. Esse parâmetro pode contribuir para o reconhecimento de possíveis impactos ambientais na área pesquisada. O parâmetro condutividade na nascente apresentou valores dentro da média sugerida para igarapés saudáveis em Manaus, com um leve aumento no período de 2005, o que pode indicar o princípio de alteração da qualidade da água na nascente.

Para os dados de 1985, em relação à área do Conjunto Residencial Petros (bairro Coroado), foram registradas discrepâncias no ano 1998, ocorrendo uma oscilação entre altabaixa-alta condutividade, o que pode indicar a entrada de efluentes. Quanto à área do Parque do Mindu, esta apresentou valores dentro do padrão (valores máximos). Apenas em 1985 e nos demais períodos, ocorreram elevadas alterações. O mesmo foi observado para o baixo curso. A tendência de alta condutividade, segundo Miranda, Silva e Pinto (2000), pode ser um indicativo da entrada de poluentes nas áreas urbanizadas que recebem esgoto domésticos e resíduos sólidos urbanos, ou seja, a crescente condutividade indica o aumento da antropização.

Já o parâmetro de Oxigênio, de acordo com Miranda, Silva e Pinto (2000) este é um forte indicador da condição da água no ambiente. Portanto, quanto maiores os valores de oxigênio dissolvido $\left(\mathrm{O}_{2}\right)$, melhor a condição da água. Conforme observado, a quantidade do $\mathrm{O}_{2}$ na nascente sofreu alterações entre aproximadamente $6 \mathrm{mg} / \mathrm{L}$ a $4 \mathrm{mg} / \mathrm{L}$, ou seja, a água apresenta condições boas dentro do padrão para as águas pretas, mesmo tendo sofrido uma leve diminuição em 2005. Todavia, os demais pontos de análise sofreram nítida diminuição. Pode ser sugerido que mesmo em áreas protegidas por onde percorre o igarapé, as medidas de proteção não foram suficientes para diminuir o processo da degradação do mesmo.

Os Compostos de Nitrogenados $\left(\mathrm{NH}^{+}\right)$íon amônio, representam um indicador eficiente, pois sua produção é resultado da degradação de matéria orgânica. Miranda, Silva e Pinto (2000) afirmam que, em ambientes naturais dos igarapés, esses teores são baixos em torno de 0,1mg. Como o nitrogênio é um nutriente que em elevadas concentrações em lagos e represas, acarreta a eutrofização, ocasiona a diminuição do oxigênio dissolvido nos corpos hídricos. O gráfico de $\mathrm{NH}^{+}$indica que os valores mais baixos foram encontrados nas nascentes, as quais estão dentro do padrão de qualidade natural.

A partir de ambientes antropizados (médio e baixo curso), os valores, aumentaram da década de 1985 a 1998 e diminuíram entre 1998 a 2005, o que poderia ser justificado pela existência da área do Corredor Ecológico Urbano de Manaus (CEUM) que, apesar de ter sido criada apenas em 2007, era um fragmento florestal preservado, livre de canalizações de esgoto 
doméstico, que pode ter sido também a causa para diminuição de $\mathrm{NH}^{+}{ }^{+}$no Parque do Mindu, localizado no médio curso.

Assim, os teores de íon amônio correspondem a valores muito acima dos padrões apresentados 3,7 mg/L (máximo estabelecido Resolução Conama nº 357 (2005) e 0,30mg/L (máximo encontrado por Bringel (1986) de maneira que a maioria dos igarapés da área urbana da cidade de Manaus encontram-se com altas concentrações do íon amônio.

Nesse estudo, foram feitas coletas entre novembro de 2011 a março de 2012 em cinco pontos: quatro nas nascentes principais, início do Igarapé do Mindu, no Parque Municipal das Nascentes do Mindu e uma no médio curso - Corredor Ecológico Urbano do Mindu/Conjunto Petros (Figura 2). Foi dada ênfase para as análises nas nascentes, pois não existiam dados publicados quanto à qualidade dessas águas, à exceção de uma nascente analisada em 2000 (MIRANDA, SILVA e PINTO, 2000).

Figura 2 - Parque Nascente do Mindu, localização coletas das amostras de água

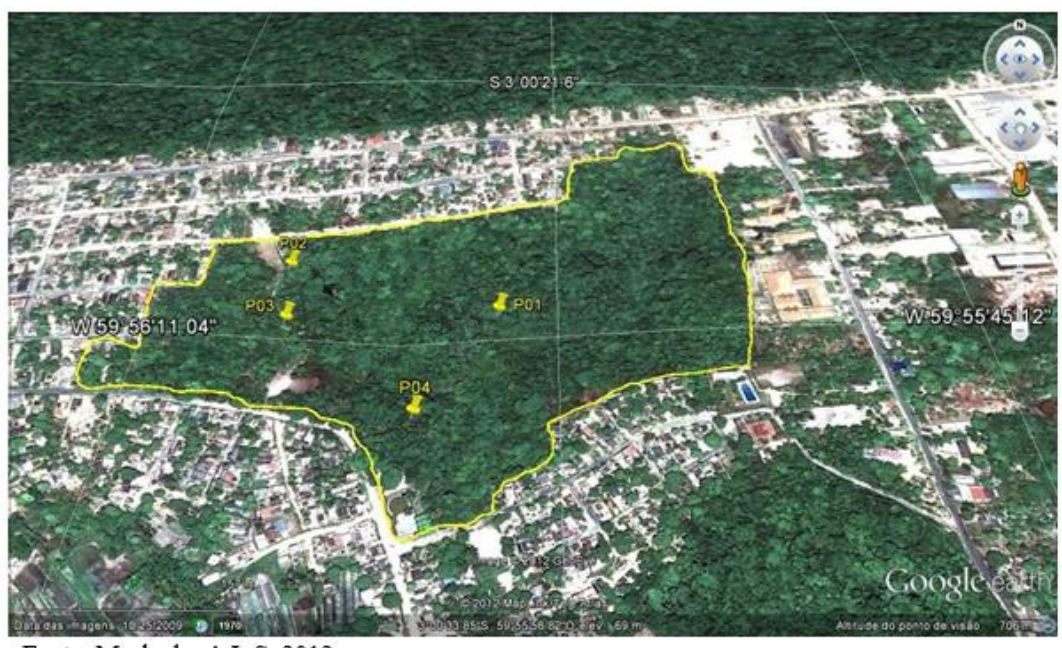

Fonte: Machado, A.L.S.,2012.

Os pontos escolhidos dentro do Parque das Nascente do Mindu (P01 e 04) são nascentes de contribuição à formação do igarapé, e o ponto (05) está numa área severamente antropizada, no Conjunto Petros. Foram realizadas análises físicas e químicas e, de acordo com a Tabela 3, as nascentes sofreram pequenas alterações em sua qualidade, conforme parâmetros analisados. 
Tabela 3 - Análise da qualidade da água do Igarapé do Mindu (2012)

\begin{tabular}{|l|c|c|c|c|c|c|c|}
\hline $\begin{array}{c}\text { Locais } \\
\text { De Coleta }\end{array}$ & $\mathbf{p H}-$ & $\begin{array}{c}\text { Turb. } \\
\text { NTU }\end{array}$ & $\begin{array}{c}\text { O.D. } \\
\mathbf{m g} / \mathbf{L}\end{array}$ & $\begin{array}{c}\text { Cond. } \\
\text { Elétrica } \\
(\mathbf{\mu S} / \mathbf{c m})\end{array}$ & $\begin{array}{c}\text { D.Q.O. } \\
\mathbf{m g} / \mathbf{L}\end{array}$ & $\begin{array}{c}\mathbf{F e} \mathbf{T} \\
\mathbf{m g} / \mathbf{L}\end{array}$ & $\begin{array}{c}\text { Fe dis. } \\
\mathbf{m g} / \mathbf{L}\end{array}$ \\
\hline P01-Nascente & 4,2 & 0,26 & 5,06 & 20,1 & 34,76 & 0,251 & 0,043 \\
\hline P02-Est_Trat. & 6,7 & 26,52 & 6,21 & 108 & 18,63 & 0,153 & 0,130 \\
\hline P03-Nasc. Lag. & 5,5 & 4,94 & 4,84 & 53,7 & 16,63 & 0,100 & 0,100 \\
\hline P04-Enc_Nasc & 6,3 & 204,62 & 6,92 & 22,1 & 19,29 & 0,513 & 0,188 \\
\hline P05-Cj_Petros & 6,6 & 23,40 & 3,60 & 281 & 22,62 & 1,036 & 0,131 \\
\hline
\end{tabular}

Fonte: Machado, A.L.S, 2012

Ao comparar os valores encontrados para $\mathrm{pH}$, verificou-se que, dentro do parque das nascentes, as únicas nascentes que apresentaram $\mathrm{pH}$ em níveis aceitáveis para água preta foram a nascente P01 e a nascente P03 (lagoa); esta pode estar com esse valor mais alto do que 5 devido ao represamento da água e à deterioração da matéria orgânica (folhas no fundo). As demais sofreram alterações; observa-se que os maiores valores foram para as águas da Estação de Tratamento; as águas da confluência e aquelas que receberam diversas cargas de efluentes domésticos (P02, P04 e P05).

Quanto ao parâmetro oxigênio dissolvido, manteve-se em padrões normais, no entanto, pôde-se observar uma relação entre o oxigênio dissolvido e o valor do $\mathrm{pH}$; eles se equivalem, com exceção do P05. Isso pode significar que o consumo de oxigênio aumentou em locais com maior entrada de poluentes, em decorrência do teor de matéria orgânica que leva a uma consequente queda na quantidade de oxigênio dissolvido disponível no corpo d'água P05.

A Condutividade Elétrica pode aumentar conforme a quantidade de íons dissolvidos; logo, é um indicador relevante para qualidade da água. Os P01, P03 e P04 indicam um estado de preservação das nascentes com pequenas alterações, ou seja, quanto menor a condutividade, melhor a condição da água.

A Demanda Química de Oxigênio (DQO) representa a quantidade de oxigênio necessária para oxidação da matéria orgânica. SILVA (1996), encontrou nas águas de igarapés da região, valores entre 20,8 a 67,0 mg/L. A concentração de DQO nestes pontos amostrados não apresentou alterações significativas entre os mesmos. O ferro, além das fontes naturais, chega aos cursos d'água por meio de esgoto doméstico e por meio de objetos descartados nos igarapés (carcaças de fogão, geladeira). Os índices para o Ferro Total, em condições naturais, são próximos a 0,200 mg/L; o que se pode observar é que o P04 e o P05 estão totalmente alterados. Para o Ferro dissolvido, os valores são inferiores a 0,100 mg/L.

O ponto P01 e o P03 demonstram ser um ambiente natural e P02 e P05 representam ambientes bastante alterados e o P04 apresentou ambiente alterado, devido a entrada da água 
P02 nesta nascente. Mesmo em períodos e pontos de coletas diferentes, ainda assim é possível relacionar a qualidade da água da primeira análise (1985) à última (2012), conforme Tabela 10, a seguir:

Tabela 4 - Análise comparativa da qualidade da água do I. Mindu (1985-2012)

\begin{tabular}{|c|c|c|c|c|c|c|}
\hline \multicolumn{7}{|c|}{ PARÂMIETROS } \\
\hline Pontos de Coleta & \multicolumn{2}{|c|}{$\mathrm{O}_{2} \mathbf{m g} / \mathbf{L}$} & \multicolumn{2}{|c|}{ pH } & \multicolumn{2}{|c|}{ C.E. $(\mu \mathrm{S} / \mathrm{cm})$} \\
\hline \multirow{2}{*}{ Curso Superior-Nascente } & 1985 & 2012 & 1985 & 2012 & 1985 & 2012 \\
\hline & 4,8 & 5,0 & 3,9 & 4,2 & 30 & 20 \\
\hline $\begin{array}{c}\text { Médio Curso - Cj. } \\
\text { Petros }\end{array}$ & 3,1 & 3,6 & 5,9 & 6,6 & 250 & 281 \\
\hline
\end{tabular}

Foi verificado que em um período de 27 anos de intervalo, a qualidade da água na nascente sofreu pequenas alterações, e permanece em estado natural. O ponto P05, no Conjunto Petros, médio curso, o nível de alterações segue levemente modificado, demonstrando que estão estabilizados os níveis de poluentes.

\section{A educação ambiental e a gestão das águas do Mindu}

A deterioração do curso do igarapé e a da qualidade das águas do Mindu são objetos visíveis da degradação ambiental em Manaus. Tanto para a população quando para o poder público há uma implícita vontade de vê-la reduzida. Por isso não apenas a forma de gestão como processos educativos são centrais nessa discussão. Para abordar a EA e a Gestão das águas, foram analisadas as leis vigentes em relação a água nos três níveis de poder. E ainda, buscou-se identificar e verificar a PNEA, a concepção de EA entre os tomadores de decisão; os programas, projetos e ações das escolas e das Unidades de Conservação da Natureza (UC's) ao longo do Igarapé do Mindu, bem como os conflitos existentes na gestão ambiental dessa área.

A concepção de EA entre os técnicos que ocupam cargos de responsabilidades nas instituições voltadas às questões ambientais e à educação pode influenciar os tomadores de decisão no que se refere às posições e deliberações a serem tomadas. De acordo com os resultados encontrados, foi analisada a EA nas perspectivas: Conservacionista e a Crítica Social, ainda no aspecto da segunda foi dado um destaque para a EA no processo da Gestão Ambiental no Município de Manaus (AM).

Tendo como base as concepções abordadas, deve haver um entendimento mais complexo quanto à EA, como um processo contínuo dentro dos órgãos gestores e sociedade 
civil. Mesmo porque ainda que entre os entrevistados a maior parte tenha como concepção a segunda abordagem, observou-se nas entrevistas um hiato entre o discurso e a práxis, quando se fala a respeito de uma concepção crítica, emancipatória e transformadora, mas as ações desenvolvidas têm um cunho voltado às ações pontuais de uso dos recursos da natureza.

Dessa forma, internalizar a concepção de EA crítica, emancipatória e transformadora, passa a contribuir mais efetivamente na construção não apenas de sujeito ecológico (CARVALHO I, 2008), mas do cidadão socioambiental (termo proposto pela primeira autora, em tese de doutorado, 2012).

No entanto, a gestão das águas, como parte de um modelo de poder público desagregado e instável procura localizar possibilidades de mudanças num processo de educação ambiental. Para os gestores entrevistados, o cenário de degradação do igarapé passa necessariamente por uma mudança de comportamento da população. É evidente que a Educação Ambiental é um processo muito importante na gestão ambiental sustentável, porque gera consciência e participação e forma um cidadão socioambiental.

A pesquisa pôde verificar que o sistema de gestão ambiental em Manaus ainda não se consubstancia em uma gestão sustentável. Já houve me gestões anteriores maiores compromissos em relação ao meio ambiente, dado a criação e atividades da Comissão Intersetorial de Educação Ambiental da Prefeitura de Manaus (CIEA - MANAUS) pelo decreto 9.287, de 28 de setembro de 2007, composta por 20 órgãos municipais da administração pública municipal direta e indireta e presidida pela Secretaria Municipal de Governo.

A criação da CIEA Manaus foi o resultado do I Fórum Municipal de Educação Ambiental de Manaus em 2007. Os objetivos da comissão eram integrar as ações de EA das Secretarias e demais Órgãos da Administração Municipal, nas mudanças de gestores, há uma descontinuidade nas ações. Ou seja, a gestão se exime de sua responsabilidade e compromisso na mudança do cenário ambiental. O que se constatou é que não existem investimentos em projetos e ações voltados à importância do igarapé àquele meio.

A gestão inepta se vale na esperança de outros processos sejam mais bem-sucedidos. Por sua, os processos educativos estão devido à falta de investimento, exceto o projeto Minduzinho, do mesmo período anterior, que se desenvolvia com recursos da Caixa Econômica Federal de forma parcial. Pouco se pode esperar de mudanças positivas em relação à degradação do igarapé. Deste modo, temos uma dura realidade à frente, um importante recurso hídrico sendo gradualmente poluído e setores de gestão e educação fragilizados. A inserção da EA como base para a gestão sustentável se apresenta sob a forma de ações pontuais e pragmáticas. 
Em todos esses aspectos, tanto a gestão quanto a educação ambiental são desafiados a criar condições para participação política em diferentes segmentos sociais, tanto na forma quanto na aplicação. É imperativo que o poder público faça a articulação e integração para o fortalecimento da gestão sustentável a partir da dimensão social e cultural nos sistemas educacionais na Secretaria Municipal de Educação (SEMED) e Secretaria Estadual de Educação (SEDUC).

Muitas escolas estão alijadas do processo transformador da EA. Das 15 escolas pesquisadas, nas proximidades (inferior à $300 \mathrm{~m}$ do leito) ao longo do igarapé, apenas duas desenvolviam projetos de EA com continuidade e resultados, à época desse estudo. Segundo relatos dos professores, faltava apoio institucional para a efetividade dos projetos a serem desenvolvidos. Pouco movimento para romper essa realidade era perceptível.

Sabe-se que é imprescindível a tomada de uma consciência ambiental e que os programas de Educação Ambiental formal e não formal podem contribuir sobremaneira na gestão ambiental. Para tanto, é preciso que haja mais articulação entre os poderes públicos e compromisso com incentivos concretos para a efetivação de uma educação transformadora.

\section{Considerações finais}

O processo de degradação dos igarapés de Manaus segue uma triste história de maus tratos e abandono tanto por parte da população quanto do poder público. Nesse estudo evidencia-se a degradação década a década da qualidade da água e dos cursos hídricos urbanos, em particular do Igarapé do Mindu. Ao longo dos 40 anos pesquisados, foram ocorrendo impactos socioambientais, consequência das ações antrópicas que tem gerado um acelerado processo de degradação no Igarapé do Mindu. A fragilidade na gestão ambiental dos cursos d'água, não apenas para com o Igarapé do Mindu, que é outro indicador dessa degradação dos cursos hídricos urbanos.

O quadro de degradação tem evoluído num processo contínuo com alterações generalizadas, tanto do leito, quanto das margens. A proteção e a conservação da cobertura vegetal são um forte critério para preservação das nascentes, tanto em quantidade como em qualidade da água. Constatou-se ainda, que as nascentes de contribuição ao Igarapé do Mindu têm uma qualidade semelhante ao estado natural. Mas diante dessa trajetória insustentável, cabe-se questionar: até quando? Faz-se mister, pois, uma mudança na relação entre crescimento da cidade e a sustentabilidade ambiental e social para mantê-las protegidas. 
A implementação de programas de EA que incluam os mais variados extratos da sociedade organizada (universidade, prefeitura, associações, movimentos sociais, organizações não governamentais, horticultores, entre outros), promovendo a participação efetiva da população nas políticas públicas voltadas para a gestão ambiental sustentável é uma demanda urgente. Para que esse desafio se torne realidade, são necessárias medidas sociais estruturantes como a criação de condições que possibilitem a melhoria da qualidade de vida dessa população que vive às margens do igarapé. Além disso, outras medidas mais imediatas são necessárias, tais como a inserção da responsabilidade compartilhada entre todos os segmentos da sociedade.

\section{REFERÊNCIAS}

BRASIL. Conselho Nacional do Meio Ambiente - CONAMA. Resolução no 357, de 17 de março de 2005. Dispõe sobre a classificação dos corpos de água e diretrizes ambientais para o seu enquadramento, bem como estabelece as condições e padrões de lançamento de efluentes, e dá outras providências. Disponível em:

http://www.mma.gov.br/port/Conama/res/res05/res35705.pdf. Acesso em: 25 mar. 2018.

BRINGEL, S. R. B. Estudo do Nível de Poluição nos Igarapés do Quarenta e do Parque Dez de Novembro. Manaus. Relatório Técnico. UTAM, 1986.

CARVAlHO I.; CARVAlHO, I. C. M. C. A Educação Ambiental: a formação do sujeito ecológico. 4. ed.- São Paulo: Cortez, 2008. 256 p.

CLETO FILHO, S. E. N. Efeitos da Ocupação Urbana sobre a Macrofauna de Invertebrados Aquáticos de um Igarapé (Mindu) da Cidade de Manaus/ AM Amazônia Central. 1998. Dissertação (Mestrado em Biologia Tropical e Recursos Naturais), Universidade Federal do Amazonas - Instituto Nacional de Pesquisa da Amazônia UFAM/INPA. Manaus. 74p.

CLETO FILHO S. E. N.; Walker, I. Efeitos da ocupação urbana sobre a macrofauna de invertebrados aquáticos de um igarapé da cidade de Manaus AM Amazônia Central. Acta amazônica, v. 31, n. 4, p. 69-89, 2001.

FEARNSIDE, P. M. Protection of mahogany: A catalytic species in the destruction of rain forests in the American tropics. Environmental Conservation, v. 24, n. 4, p. 303-306, 1997.

FONSECA, O. S. M.; SALEM, J. I.; GUARIM, V. L. Poluição e autopurificação do Rio Negro nas cercanias de Manaus. Acta amazônica, v. 12, n. 2, p. 271-278, 1982.

JUNK, W. J. As águas da Região Amazônica. In: SALATI, E.; JUNK, J. W.; SCHUBART, H. O. R.; OLIVEIRA, A. E. (eds.). Amazônia: desenvolvimento, integração e ecologia. Editora Brasiliense, SP, 1983. p. 14-44. 
MACHADO, A. L. S. Educação Ambiental para Gestão Sustentável da Água: estudo de caso do Igarapé do Mindu - Manaus, AM. Tese (Doutorado em Educação), Centro de Desenvolvimento Sustentável, UnB, 2012.

MANAUS. Lei Municipal ${ }^{\circ}$ 671, de 04 de novembro de 2002, o Plano Diretor Urbano e Ambiental, estabelece diretrizes para o desenvolvimento da Cidade de Manaus e dá outras providências relativas ao planejamento e à gestão do território do Município.

MELO, E. G. F.; SILVA, M. S. R.; MIRANDA, S. A. F. Influência Antrópica sobre águas de igarapé na Cidade de Manaus - AM. Caminhos de Geografia - revista on line, v. 5, n. 16, p. 40-47, out., 2005. Disponível em: http://www.ig.ufu.br/revista/caminhos.htm. Acesso em: nov. 2017.

MIRANDA, S. A. F.; SILVA, M. S. R.; PINTO, A. G. N. Hidroquímica das Águas - Bacias Hidrográficas do Município de Manaus (AM). In: Relatório Informativo - Projeto:

Avaliação dos Recursos Hídricos da Região Metropolitana de Manaus, período: 1997 - 2000. Manaus: INPA, 2000.

NOGUEIRA, A. C. F.; SANSON, F.; PESSOA, K. A Expansão Urbana e Demográfica da Cidade de Manaus e seus Impactos Ambientais. Anais [...] do XIII Simpósio Brasileiro de Sensoriamento Remoto, Florianópolis, Brasil, INPE, p. 5427- 5434, abril-2007.

OLIVEIRA, J. A. Meio Século de Transformações e Permanências: a cidade no Brasil (1930 a 1980). In: SPOSITO, M. E. B. (org.). Urbanização e Cidades: perspectivas geográficas. Presidente Prudente: UNESP, 45 p. 2001.

PINTO, A. G. N. et al. Efeitos da contribuição antrópica sobre as águas do rio negro, na cidade de Manaus, estado do amazonas. Caminhos de Geografia, v. 10, n. 29, p. 26-32, jun. 2009.

SILVA, M. S. et al. Hidroquímica e Metais na Água, Sedimento e Comunidades Biológicas em Bacias Urbanas no Município de Manaus (AM). XVII Simpósio Brasileiro Recursos Hídricos, 2007, São Paulo. Anais do XVII Simpósio. Disponível em: www.abrh.org.br/novo/XVII_simp_bras_rec_hidric_sao_paulo.php. Acesso em: 10 out. 2012.

\section{Como citar este artigo:}

MACHADO, Ana Lucia Soares; ZANETTI, Izabel C. B. B.; HIUGCHI, Maria Inês Gasparetto. A degradação dos cursos hídricos urbanos, uma abordagem sobre gestão e educação ambiental. Revista Ibero-Americana de Estudos em Educação, Araraquara, v. 14, n. 3, p. 1124-1138, jul./set., 2019. e-ISSN: 1982-5587. DOI: 10.21723/riaee.v14i3.11416

Data de Submissão: 21/05/2018

Revisões requeridas: 20/08/2018

Aceite em: 30/11/2018

Publicado em: 10/05/2019 